\title{
Brain Circulation, the Phenomenon and Challenges
}

\author{
Lajda Bana \\ University of Tirana, Faculty of Law
}

\begin{abstract}
The world of today which seeks globalization, while the economic inequality, corruption, political instability, and moreover wars prevail, it is always associated with the movement of people towards what might be called the 'best for their future'. This movement is not just a mechanical action, but is a phenomenon associated with social, economic and political consequences not only to the country of origin but also for the host country. The departure of the people from their land is a well-known and proven phenomenon mainly of the developing countries. This phenomenon includes also the so-called brain drain emigration, the departure of skilled people, professionals and researchers from their own country to other places. The brain drain is not only a phenomenon that belongs to developing countries, or former communist states, or those countries in war, but it can also affect the developed Western countries. Brain drain does not always constitute a brain gain in the host country. In most of the cases, people who have to leave the countries in political instability or former communist countries, even if they are qualified and holders of university degrees, they are obliged to work in humble jobs which can be simply exercised by persons without university qualifications. Consequently, the brain drain phenomenon is not automatically turned into a benefit 'brain gain' for the host country; on the contrary, it might even be turned into the so-called brain-waste. A social challenge in this context remains the turn of "brain drain" into "brain gain" or "brain circulation". Therefore, one of the current priorities for governments is to create effective economic and social conditions which would enhance the integration of the graduates, researchers and professionals into their national and regional markets
\end{abstract}

Keywords: Brain drain, brain gain, fund of excellence, economic growth, development.

\section{Introduction}

This article will treat and examine the phenomenon of human capital flight or brain drain, a phenomenon which is widely encountered in developing countries as well as in the developed ones. It will also provide an analysis of the main factors, which lead to the phenomenon of brain drain and its crucial consequences. Skilled migration is nowadays a known trend of migration patterns, which seems fueled by the development of the economy and the emergence of a global labor market demanding for skilled professionals. Migration is also a major concern for the less developed countries, which experience mostly the concern of negative consequences of the loss of their citizens, who are professionally capable in terms of contributing to the economic and human development. Albania, as a developing country in its transitional period encountered this phenomenon for its first time, after 90'. During this period, a substantial part of the phenomenon of the national migration, it was consequently accompanied by the brain drain process. Many qualified people including university professors, decided to leave Albania and migrate to western countries. Since 1997, there have been continuous efforts to tackle this phenomenon and to facilitate the return of the brain, by creating incentives starting from the reduction of the bureaucratic recruiting procedures in public and private sectors, to the fund raising initiatives even from the state budget sources specifically to facilitate the brain circulation of scholars. It's worth mentioning, two of the Albanian Government's programs, that of Brain Gain program and the Fund of Excellence which will be further elaborated in this article.

\section{General factors that lead to a brain drain occurrence}

Among the main factors that could cause the phenomenon of brain drain is commonly the aspiration and choice of individuals to strive for new economic perspectives, broader spaces in their professional career and above all, attaining higher incomes and better living standards.

These factors have been categorized into two main types: first, there are the factors related to national context, the socalled internal factors of the country of origin which push toward immigration (i.e., push-factors), such as the lack of employment opportunities, low wages, economic instability and the aspiration to have a well-recognized qualification by a 
world-class system of higher education, and second type, those external factors which are related to the favorable conditions and level of the wellbeing of the host countries which frequently attract the immigrants.

The continuing increase of youth unemployment rate evidently in the countries of Southern and Eastern Europe pushes predominantly the university graduates of this region to seek professional opportunities primarily abroad. Brain drain causes serious consequences foremost for the central government, since it invests public money to provide further qualifications to the young people, in order to better respond to labor market demands and to contribute to the economic development of the country both, in the public and in private sector. So, this type of loss in this case can be called a crosscutting one which effects respectively: the economic, human and social aspects.

Brain drain, as a phenomenon across states, markets, and people should not be considered and cannot be analyzed solely as an economic issue and effecting only a given context. To this point, it appears that the brain drain is not only a problem for developing countries but it influences even the developed ones.

\section{The elements that have contributed to the growth of brain drain phenomenon}

\section{Economic Crisis (2007)}

The phenomenon of brain drain has been more vulnerable to Europe especially since 2007, when the economic crisis had its major effects in some Southern European countries like Greece, Spain and Portugal, accompanied by the integration of Romania and Bulgaria into the European Union. A considerable number of the well-qualified populations of these countries decided to move to other European countries. Consequently, the most effected regions by brain drain phenomenon remain the countries located in Southern Europe (Greece, Spain and Portugal) typically because of the high level of unemployment rate of educated and qualified individuals and in particular youth, followed by some countries in Eastern Europe, (Romania and Bulgaria), where principally the low salaries in education, research and medicine sector have caused exodus of the population towards western countries. In this context, Romania is significantly affected by the migration of doctors and nurses from its national health care system, subsequently bringing a reduction of qualified staff in this sector. Further, in Spain, the reduction of the state budget funds dedicated for education and research induced the dismissal of a large number of employed professionals and researchers. Concerning the negative consequences of this immigration on the Spanish economy and society, there was organized a meeting of 50 Rectors of Spanish Universities in December 2012, who appealed to the political class that if they would continue to cut the education budget, this would harm in return the future of the country and would leave thousands of young researches without a professional perspective thus, consecutively would lead to the deterioration of the Spanish economy's future. (Morel, 2013)

Regarding the Greece situation, it is definitely the case when it can be stated that it is the most affected country by the economic crisis, where its unemployment rate reached the highest figures of 56,8 \%, in the period from March 2014. Therefore, the economic instability has turned brain drain into a real problem for the governmental structures in this country.

\section{Expansion of the European Union mainly with Balkan countries}

The expansion of the European Union with countries from Eastern Europe such as Bulgaria and Romania has caused the aggregate of the brain drain phenomenon towards the western countries. The consequent immigration in these cases undermines the respective future progress of these countries and their obligations to better respond to union duties. Good parts of the displaced population choose United Kingdom. In an article of «The Guardian" by Ivan Krastev (March 24, 2015), the author stated inter alia that immigration is damaging Bulgaria, at a time when this country needs qualified and professionals.

Here's a popular joke doing the rounds in Bulgaria at this period, which is extracted from the above mentioned article. "Three Bulgarian men, dressed in traditional Japanese costume and armed with swords, are walking down a street in Sofia. One of the passersby asks them who they are and what they want.

"We are the seven Samurai and we want to make this country a better place," say the men.

"Why are there only three of you then?" 
"The other four are all working abroad1."

The opening of borders was something considered good and bad. Mass migration of people aged between 25 and 50 years has severely damaged economic and political system of this country. A part of the young people, prefer to earn more by taking care for a family in London than to work with a low-paid to their country, and exercising their own professions. However, Bulgarians, but mostly not only them prefer to work abroad and alongside carry out their studies. Apart of the Chinese, the Bulgarians are the second largest community of foreign students in Germany. So, apparently, the most active and critical citizens left their country, leaving behind only 'three Samurais' to make a difference and the enhance progress in the country.

The brain drain is not a new phenomenon at a certain period of time. Over the years, professionals and scientists always have moved for centuries seeking better work conditions and opportunities, in the most developed countries. United States and Canada because of their legal frameworks concerning immigrants have been the most preferred destinations for foreign intellectuals. But, it is worth noting that in addition to that, the top level universities located in both countries have also attracted foreign students and keep doing so by offering professional development opportunities for future careers to all candidates.

Brain drain in the European Union (EU) is potentially possible and supported by the right of free movement and employment of citizens across European countries. The fundamental principle guiding these procedures allows these people to live and work wherever they want within the boundaries the EU.

It is very important for national authorities to find opportunities and effective tools to prevent the brain drain and adjust the ratio of the workforce with higher education qualification among all Member States of the European Union in order to ensure and stimulate sustainable economic growth within the union.

\section{Some data of Brain Gain phenomenon, according to the reports of international organizations ${ }^{2}$}

According to a recent report of the Organization for Economic Cooperation and Development (OECD) "Immigration World in Figures" (2013) emigration of professionals skills qualified (certified) is increasing rapidly, leading to figures of about 232 million migrants worldwide. The United States, Russia, Germany, Saudi Arabia, UAE, United Kingdom, France, Canada, Australia and Spain, according to the 2013 report were the host countries, where there have been placed more than half of the all international migrants. According to OECD-UNDESA, the number of migrants with tertiary education in the OECD increased to $70 \%$ in the past decade, reaching to 27 million migrants in $2010 / 2011$. About $30 \%$ of all migrants in OECD countries were highly educated.

One in every 9 (nine) persons with higher education (university) born in Africa, lived in OECD countries in 2010/2011. The corresponding figures for Latin America and the Caribbean, Europe and Asia have been respectively 1 (one) to 13 (thirteen), and 1 (one) to 30 (thirty).

Brain drain is particularly acute in small countries and island states which part of Africa, Latin America and the Caribbean. In 2010 , nearly $90 \%$ of people with higher education and training born in Guyana lived in the OECD countries. On the other hand, in contrast to this fact, most OECD countries as well as non OECD countries with large populations, including Brazil, China, India and the Russian Federation, had rather low emigration rates of highly-skilled population which was approximately less than $3.5 \%$.

Over the past ten years, the emigration of highly-skilled workers has increased for some countries, while it has decreased in others. While the absolute number of migrants with tertiary education in OECD countries has increased, from all countries of origin, in some cases, the number of people with higher education in countries of origin, rose faster than the number of highly educated immigrants.

1 http://www.theguardian.com/commentisfree/2015/mar/24/britain-east-europe-brain-drain-bulgaria

2 Immigration World in Figures" (2013) http://www.oecd.org/els/mig/World-Migration-in-Figures.pdf 


\section{Negative and positive consequences of the brain drain}

Brain drain as being studied today by a group of economic analysts, it does not only bring negative consequences, because some of those who had to emigrate, if returned to their country, they have gained more professional skills. In some other cases, displaced people are unemployed or employed not in their own profession in their country of origin, so their departure cannot be considered a great loss to the sending country.

On the one hand, the exodus of professionals, scientists, students, information technology engineers, medical staff and researchers from south to north and from east to west, has rather straight negative consequences on the economy and society of the countries of origin.

But in other cases, the departure of skilled workers from one country is offset by the arrival of skilled workers from other countries, as this phenomenon has been described in one of the Chapters of the OECD report "Trends in International Migration "(2004). The typical case of this domino effect is the movement of the medical professionals into the developed countries meanwhile this contingent of professional is being replaced with doctors coming from Cuba. For very poor countries, such as Cuba for example, prospects for emigration may enhance incentives to increase the level of education and qualifications enabling additional funds to be invested in the education sector. When the 'Brain Gain' within a country is higher than 'Brain Drain', the impact to strengthening of the welfare level and development of the country can be extremely positive. With the manifestation of brain drain, the education level and contribution of those who remain in the country may be higher than what it would be in case of no migration at all. Moreover, it is important to understand that the brain drain cannot only be used to tell that part of the story about the overall impact of immigration on the economy and society, but it also can result into other impacts such as remittances, inward investment, transfer technology, increasing the flow of trade, donations supported by diaspora community. Therefore, it should be considered and recognized that the impact of this phenomenon can somehow be positive too.

The negative effects of brain drain phenomenon are not only economic but also social ones. The countries with significant loss of the brain can experience decrease of production, lack of innovation and reduce of well-educated human capital, and increase in the number of overqualified employees. In the case of Eastern European countries, the brain drain has created a reduction of professionals in the labor market, mainly in the field of medicine, scientific research and information technology. On the other hand, there are several benefits associated with their countries of origin, such as remittances, creating scientific and business networks, as well as the possibility of potential returning of emigrants with more professional skills, earned abroad.

Remittances are very important for developing countries as in the case of Albania. Remittances are an important source of poverty reduction and economic growth. Remittances ${ }^{1}$ in Albania had increased from \$ 377.9 million EUR in 1994 to \$ 780m in 2003 and to 951.7 million EUR in 2007. Further, the remittances have suffered a big drop, especially after the deepening economic crisis of Eurozone. During 2014, the remittances resulted in the figure of 592 million EUR, compared with 951.7 million EUR in 2007. These figures confirm the decline in the contribution of remittances in the national economy, as the economic crisis in Europe has significantly decreased in parallel their income.

\section{Policies undertaken by the Albanian Government for the return of highly-skilled employees}

The brain drain is not unknown for Albania. After the fall of the communist regime, thousands of Albanians fled to developed countries. During ' 90 , almost $40 \%$ of lecturers and researchers left the country. Among them $66 \%$ were holders of an academic title "Doctor of Science" (Ph.D.). Equally, there are many cases of experts and students who chose to study in different countries such as in Greece, Canada and Germany, among whom it is estimated that only $5 \%$ of them return. Albania is one of the Eastern European countries with a high level of brain drain, a phenomenon that has accompanied this country during its transition period. Albania has faced twice a massive brain departure, the first one in the early ' 90 s mainly

1 http://open.data.al/sq/lajme/lajm/lang/sq/id/1443/Remitancat-2002-2014-origjina-sipas-vendeve 
for economic reasons and the second one in the period of 1997-1999 due to the political instability caused by the so-called pyramid schemes.

According to a study conducted by the Center for Economic and Social Studies, supported by the Open Society Foundation for Albania, in the period 1991-1998 about 31.45\% of experts with higher education level had left Albania, while $63 \%$ of the respondents in this study expressed the desire to emigrate. Each year about 2000 students leave the country to study abroad in foreign universities. The major reasons that drive Albanians to leave the country are not only the internal factors but as it has also been defined, the people are significantly influenced by the external factors. Albania is a country of the Western Balkans with a high rate of immigration where about $30 \%$ of families have members living abroad, serving to pull the rest of the family members. Similarly, the most attractive factors for the group of immigrants with high professional skills remain the necessity to ensure better knowledge and sharing of their academic and scientific work outputs. To respond to this phenomenon, constant measures have been undertaken by the Albanian Government in particular through its program called "Brain Gain" which aimed at returning of scholars and encouraging the return or bridging the stay specifically for the highly-skilled professionals and experts.

In 1997, Mr. George Soros donated \$ 1 million to support the development and modernization of public administration in Albania through the process of increasing the wages of those people who came to work in the administration with Master's degrees, earned abroad at foreign universities. This project lasted six years and was extended to public administration levels of the local government units. According to the data emerging from various studies, about 150 people have benefited from this program. These studies have shown that increases in wages (sometime doubling or tripling of salaries) of civil servants is not fully an effective tool for developing human resources in the state administration. These data are part of several studies and reports carried out by the Soros Foundation to evaluate the effectiveness of this financial scheme during 2005.

The "Strategy for the promotion of employment for students who are employed abroad" in 2004, defined several improvements of the legal framework in the field of recruitment to give more priority to those who had studied abroad. The document included provisions which facilitated procedures aiming at"... providing the best choices in favor of improving the recruitment process, which would give priority to employment of those candidates who had studied abroad, without prejudice to the principles of equality, trust and non-discrimination " and "...giving priority to people who belonged to this category, in the case of selecting three best candidates by the ad hoc committees on a base of the competition procedures...

\section{Brain Gain Program}

The 'Brain Gain Programme' (BGP), is a cooperation program between the Government of Albania and United Nations Development Program (UNDP), which dates back to April 2006. BGP is an executive national project, funded by UNDP with about (40\%) and the Albanian Government (60\%). This program addresses the diaspora and graduates from recognized foreign higher education institutions with a Master and PhD degrees. Diaspora with Albanian origin established during the last decade of 20th Century and it is represented by a group of qualified individuals who contribute professionally in different sectors, to advances science and technology, in countries where they have emigrated. The contribution of the Diaspora in the development of country of origin is a proven reality and stands for the case of Albania. The income that entered in the country in form of remittances is a visible impact. In this context, the withdrawal of this group of people, to Albania remains a priority for the persistence of development of the country. The objective of BGP was i) to provide support to the government in creating and promoting elements of mechanisms of policy-making and ii) to effectively enhance the engagement of diaspora and skilled emigrants in the development of scientific research sectors, administrative and economic development.

During the period 2008-2011, the program has supported with reintegration financial package about 137 individuals who returned to Albania or have given their contribution as visiting professor at various academic institutions in the country. Diaspora as the intellectual capital of the highly qualified migrants returning to the country has been considered as a valuable asset for Albania in its path towards integration into the European Union. Despite their contribution in building the human capital of Albania, these individuals have shown that they have appropriate professional potentials to stimulate research and development of technology in the country. 
Brain Gain Program with its direct achievements to enable return and reduce loss of professionals, it has also made somehow possible to curb the Albanian Brain Drain. Additionally, with its encouraging schemes, this program has made possible the return of 137 individuals highly qualified in various sectors in the country. It has in some ways institutionalized the real opportunity of the return for other individuals and highly qualified candidates to come and be employed in various sectors in Albania.

Table:Data of the BG program beneficiaries (scientific level, the sectors of employment, etc.)

\begin{tabular}{|c|c|c|c|c|c|c|c|}
\hline \multirow[t]{2}{*}{ Institutions } & \multirow[t]{2}{*}{ Individuals } & \multirow[t]{2}{*}{ Female } & \multirow[t]{2}{*}{ Male } & \multicolumn{2}{|l|}{ Female } & \multicolumn{2}{|l|}{ Male } \\
\hline & & & & Master & $\mathrm{PhD}$ & Master & PhD \\
\hline Public Administration & 21 & 7 & 14 & 7 & - & 12 & 2 \\
\hline Public Universities & 57 & 24 & 33 & 13 & 11 & 17 & 16 \\
\hline Private Universities & 20 & 8 & 12 & 2 & 6 & 8 & 4 \\
\hline Visitor Professors & 39 & 10 & 29 & 4 & 6 & 12 & 17 \\
\hline Total & 137 & 49 & 88 & 26 & 23 & 49 & 39 \\
\hline
\end{tabular}

The Albanian Government, in accordance with its development program, it has planned to reorganize the concept of this program in the Program of Brain Circulation by December 2016 aiming at enhancing the contribution of Diaspora by increasing the number of the returned professionals in the country.

\section{Fund of Excellence Program}

Fund of Excellence Program was created in 2007, as one of the Albanian State objective to financially support Albanian excellent students, who have been accepted for doctoral and post-doctoral studies abroad, or authors for their publications in journals with impact factor, prices for the participation in international Olympiads. Periodically this program has been change. In 2010, the range of applicants to this program was expanded, including students who will attend the studies in top 15 universities in the world, at the level of Bachelor and Master. To respond to membership of the country in NATO in 2010, priority was given to specific fields such as National Security.

During 2012, the Council of Ministers has determined that the categories of beneficiary candidates will be the students who would enroll at Bachelor, Master and Doctorate programs. In July 2014, the Council of Ministers defined changes to the program determining the ranking of the host universities would refer to international classification published by Times Higher Education Ranking. Further, in the framework of capacity buildings within the public administration reform, this program included the category of civil servants, who can apply for financial support in case that they are admitted to perform master studies (duration of one year) at the top 300 universities according to the Times Higher Education Ranking in the following fields:

- Education policies;

- Health policies;

- Public policies;

- Urban development;

- Management and public finances;

- $\quad$ Administrative Law / Public;

- $\quad$ European Studies.

According to the Ministry of Education and Sports, in the framework of this program for the period 2007 - 2015 there have been financed about 200 individuals. The major fields, in which the successful candidates of this program have studied or continue to study, are Health, Economic Science, Engineering, Computer Science, Law etc. 
The main obligation for the beneficiaries of this program is that after completion of studies they have to return and contribute to implement the competencies acquired, in the respective sectors, for at least 3 years. In those cases, when the beneficiaries are students of the first cycle or second cycle, this program allows the continuation of the studies at the next level to the end of all cycles of university studies. The categories of civil servants, at the accomplishment of their studies have to work in Albania for at least 4 (four) years in the Albanian institutions. The major objective of this program is to create excellence by funding the study of excellent students, supporting their education in the best universities and enable them to contribute in Albania, in public and private sector, by increasing the level of scientific research and innovation. Most of the beneficiaries of this program who have completed doctoral studies are currently employed and exercise their professions in the institutions of higher education.

The Albanian Government through the Ministry of Education and Sports has made available to Albanian excellent students a fund of 150,000,000 ALL per year according to the relevant decision of the Council of Ministers No 483, date 16.07.2014.

What might be called the challenges of this program today? The success of the program would be related to the employment of graduates in the respective sectors. Presently, apart from the obligation to return and work in Albania, there is no written regulation how to improve the procedures and create more possibilities in recruiting these young professionals.

The Prime Minister of Albania, Mr. Edi Rama, during his official visit to the United States in September 2015, had the opportunity to meet with activists of the Albanian - American community and partners of the Centre for International Development, Harvard, focusing on gaining further support to enhance joint studies between Albanian-American community and finding ways of involving experts from this community into the activities of political and social life in our country. In this context, the Albanian Government will work with all stakeholders to make possible the organization of the first Summit of the Albanian Diaspora around March 2016 in Tirana.

\section{Conclusions}

Despite the fact that Albania has been affected by the phenomenon of brain drain, we need to recognize that we are a country with great desire and aspirations to be educated, to be eligible to prepare experts and young professionals who would be able to respond not only to the national labor market but to also be integrated into regional and European one.

In this context, it remains crucial to support the return of qualified Albanians living abroad and to better facilitate the cooperation with diaspora. Enhancing quality in higher education institutions to make Albanian diplomas competitive in the global market, and foster the modernization and internationalization of higher education institutions, in order to make it more attractive for young Albanians inside the country and abroad as well as for foreign students, remains a key element.

Albania as a country that has already got the status of candidate country for membership in the European Union, has an indispensable requirement to support the young Albanians who have been educated abroad, as well as to involve the qualified professionals, engaged abroad, to bring home their contribution in the preparing the legal framework in alignment with European Directives, by directly contributing to the development of key sectors of economy and technology. This would enable the real circulation of knowledge and science, the so-called 'brain circulation' by implementing the up-to-date experiences developed abroad, to support the realization of national reforms and the practical application of the legal framework across sectors.

\section{References}

1. http://www.migrationpolicy.org/article/skilled-migration-abroad-or-human-capital-flight

2. http://communicate-europe.co.uk/fileadmin/files_emi/EMI_Members_News/EM_Armenia/EMA_Policy_Paper_Brain_Gain_Policies.pdf

3. http://erawatch.jrc.ec.europa.eu/erawatch/opencms/information/country_pages/al/supportmeasure/support_00 $\underline{01}$

4. http://www.telegraph.co.uk/news/worldnews/europe/eu/11673994/Back-my-migration-reforms-to-halt-theEuropean-brain-drain-urges-David-Cameron.html

5. http://r4d.dfid.gov.uk/PDF/Outputs/MigrationGlobPov/Brain_Gain.pdf 
6. http://www.grupa484.org.rs/sites/default/files/Od\%20politika\%20do\%20praksi\%20priliva\%20mozgova\%20\%20\%C5\%A1irenje\%20najboljih\%20institucionalnih\%20praksi\%20u\%20regionu\%20Zapadnog\%20Balkana, \% 202014.pdf

7. http://www.undp.org/content/dam/undp/documents/projects/ALB/00044131_Brain\%20Gain\%20ProDoc.pdf

8. http://europa.eu/rapid/press-release_IP-14-538_en.htm

9. http://europa.eu/rapid/press-release_MEMO-13-558_en.htm

10. Decision no 483, date 16.07.2014 of Council of Ministers "For the financial support of excellent students and civil servants of the State Administration (Fund for Excellence)";

11. Decision no. 57 date 1.2.2012 of the Council of Ministers "For the approval of action plan of Brain Gain Program, for the period 2012-2013"

12. Instruction no. 16, dated 01.08 .2014 of the Minister of Education and Sports "On the criteria, measures and procedures for the beneficiaries of Excellence Fund for excellent students and employees of the state administration";

13. http://www.theguardian.com/commentisfree/2015/mar/24/britain-east-europe-brain-drain-bulgaria

14. http://www.nytimes.com/2015/03/10/opinion/embracing-the-other-italy.html? $\mathrm{r}=0$

15. http://www.oecd.org/els/mig/World-Migration-in-Figures.pdf

16. http://open.data.al/sq/lajme/laim/lang/sq/id/1443/Remitancat-2002-2014-origjina-sipas-vendeve 